\section{P533 CHILDHOOD OBESITY AND CIGARETTE SMOKING DURING PREGNANCY}

Anwar Ayubi ${ }^{*}$, MAS Ahmed, Olajumoke Davies. BHRUT, Romford, UK

10.1136/archdischild-2019-epa.868

Objective The aim of this study is to examine if cigarette smoking during pregnancy is a risk factor of childhood obesity.

Methods This is a hospital based observational study over a period of 5 years. Data was collected prospectively in clinic setting. Diagnosis of obesity was based on the agreed national definition (BMI >95th centile). Main outcome factors are cigarette smoking during pregnancy, birth weight, family history (FH) of obesity, regular moderate weekly physical activity, daily duration of TV viewing, daily fruit and/or vegetable intake, diet and eating habits.

Results Cigarette smoking during pregnancy was confirmed among 68/728 (9\%) obese children. 45/68 (66\%) females and 9/68 (15.5\%) were of ethnic origin. 58/68 (85.5\%) developed obesity after age of 3 years. 61/68 (90\%) were born with normal birth weight. The remaining children had birth weight of $<2.5(\mathrm{n}=4 ; 6 \%)$ or $>4.5 \mathrm{~kg}(\mathrm{n}=3 ; 4 \%) .42 / 68(62 \%)$ with positive $\mathrm{FH}$ of obesity. 52/68 (76.5\%) watched TV more than 2 hours a day and 30/68 (44\%) children carried moderate physical activity of $<4$ hours a week. Dietary assessment revealed that $54 / 68(79.5 \%)$ children consumed $<3$ fruits or portions of vegetables a day, and 53/68 (78\%) children consumed high calorie intake.

Conclusion Obesity among children of mothers with a history of cigarette smoking during pregnancy is multifactorial and cigarette smoking during pregnancy does not seem to be a major risk factor of childhood obesity. Our study is a hospital based one; therefore, its broad view should not be formally accepted without support by other population based study.

\section{P534 HOW COMFORTABLE ARE THE DOCTORS IN GALWAY UNIVERSITY HOSPITAL PAEDIATRIC DEPARTMENT WITH DISCUSSING WEIGHT IN CHILDREN WITH OBESITY?}

Dr Hope Murphy O'Connor*, Dr Niamh McGrath. Galway University Hospital, Galway, Ireland

\subsection{6/archdischild-2019-epa.869}

Background Obesity a serious and complex health problem affecting a large number of paediatric patients both in Ireland and internationally, over 124 million children are affected by obesity worldwide. ${ }^{1}$ In order to address this growing problem it is vital paediatric doctors are comfortable addressing weight issues in children. We undertook this study to discover the current practices in our paediatric department and identify areas for improvement.

Aim To assess the level of comfort among doctors in the paediatric department in Galway University Hospital (GUH) in addressing childhood obesity and determine their current clinical practice regarding investigation and management of obesity.

Material and methods The study was conducted among doctors working in GUH paediatric department in January 2019. The doctors answered questions about their level of comfort discussing obesity, factors that prevented them from being comfortable, and their current strategies for investigation, management and follow up for children with obesity.
Results Of the 27 member of the staff who took part in the study only $6(22 \%)$ were very comfortable addressing weight concerns with parents and patients. Lack of knowledge of appropriate services and resources for obese children and their families was the most common reason clinicians gave for not being comfortable addressing the subject (33\%).

All of the doctors surveyed all believed outpatient clinic to be an appropriate place to address weight issues with families $(100 \%)$. Few believe the emergency department to be an appropriate place to address the issue (18\%).

All the doctors studied provided exercise and dietary advice to families (100\%). With a smaller number also providing information about healthy sleep habits (29\%) and reducing screen time (48\%).

The most commonly referral was to the Dietetics department $(48 \%)$ and a large number were referred back to their General Practitioner (29\%) to follow the patient's progress.

Conclusion As obesity among the paediatric population is an increasing concern it is vital for doctors working in paediatric departments to be knowledgeable and comfortable managing obese patients.

We have identified a lack of knowledge of resources and services for this population to be a barrier in providing the best care for these patients and their families. We intend to address this problem going forward by providing education to all doctors in the department.

\section{REFERENCE}

1. NCD Risk Factor Collaboration (NCD-RisC). Worldwide trends in body-mass index underweight, overweight, and obesity from 1975 to 2016. The Lancet. 2016;390 (10113):P2627-P2642

\section{P536 MODERN OPPORTUNITIES FOR VACCINATION PCV13 IN CHILDREN SUFFERING CHRONICAL INFLAMMATION NASOPHARYNGEAL DISEASES USING RECOMBINANT $\alpha 2 B$-INTERFERON}

Vera Vavilova*, Aleksandr Vavilov, Anastasia Cherkaeva, Irina Nechaeva. HEKSMU, Kemerovo, Russian Federation

\subsection{6/archdischild-2019-epa.870}

Aim To study the efficiency of recombinant $\alpha 2 b$-interferon (Viferon gel) in preparation and conducting vaccination with PCV13 in children suffering chronical inflammation nasopharyngeal diseases.

Materials and methods 1256 children aged 2-5 suffering chronical inflammation nasopharyngeal diseases $100 \%$ were observed. To prepare for the vaccination with PCV13 children in core group $(n=631)$ were prescribed with $\alpha 2 b$-interferon (endonasally and on palatine tonsils 2 times a day - 10 days before and 30 days after the vaccination). In the control group $(n=625)$ they weren't given $\alpha 2 b$-interferon. Comparative analysis of morbidity before and after the vaccination within 12 months' time was conducted.

Outcomes All the children observed come from the group of those often suffering from recurrent respiratory infections. On assessing the proportion of children who lapsed into illness by the time the vaccination was conducted, in the core group all the children were vaccinated on time; in the control group $13.4 \%$ of children didn't come to vaccination because of the severe respiratory infection $(\mathrm{p}=0.000)$. Within 1 month after the vaccination in the core group $4.8 \%$ of children lapsed into illness, in the control group - 12.8\% ( $p=0.000)$. 